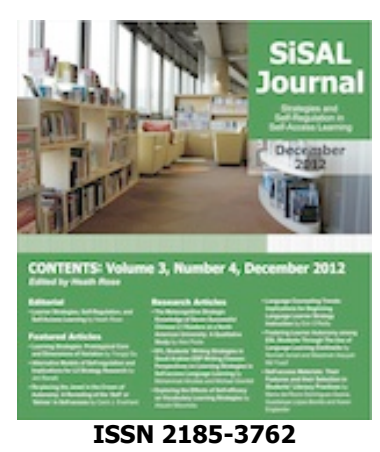

Studies in Self-Access Learning Journal

http://sisaljournal.org

\title{
Language Counseling Trends: Implications for Beginning Language Learner Strategy Instruction
}

Erin O'Reilly, Defense Language Institute Foreign Language Center, USA

Corresponding author: erin.n.oreilly@us.army.mil

Publication date: December, 2012.

\section{To cite this article}

O'Reilly, E. (2012). Language counseling trends: Implications for beginning language learner strategy instruction. Studies in Self-Access Learning Journal, 3(4), 438-451.

\section{To link to this article} http://sisaljournal.org/archives/dec12/oreilly

This article may be used for research, teaching and private study purposes. Please contact the author for permission to re-print elsewhere.

Scroll down for article 
SiSAL Journal Vol. 3, No. 4, December 2012, 438-451

\title{
Language Counseling Trends: Implications for Beginning Language Learner Strategy Instruction
}

Erin O’Reilly, Defense Language Institute Foreign Language Center, USA

\begin{abstract}
This paper summarizes a qualitative, exploratory research project using archival data from language counseling reports written for adult, Arabic foreign language learners $(N=19)$ enrolled in weeks $1-10$ of an intensive, academic Arabic language program at a West Coast school in the United States who attended a language counseling session at a self-access center. The goal was to analyze reports for possible trends in students' needs using Oxford's (2011) Strategic Self-Regulation $\left(\mathrm{S}^{2} \mathrm{R}\right)$ model as a framework to better inform targeted strategy instruction for this population. The study used a two-cycle coding method. Descriptive codes were developed using a constant-comparison approach for first cycle coding. An axial coding approach was used for the second cycle, where the descriptive codes were collapsed into four major themes analyzed using frequency counts. Results indicated that students struggled with vocabulary, aural input discrimination, study management, and stress. Discussion includes practical applications for language counselors. Limitations and suggestions for future research related to trend analysis and the $\mathrm{S}^{2} \mathrm{R}$ model in language counseling are discussed.
\end{abstract}

Keywords: language advising, language counseling, metacognition, self-management, strategic self-regulation

\section{Framing Learning Strategies}

Traditionally, research on language learning strategies has focused on students' strategy use, awareness of strategy use, and strategy instruction as each element relates to language proficiency development (Cohen, 2007). The recent dialogue on language learning strategies has moved to the more encompassing concept of self-regulation (Dörnyei, 2005). The assumptions here are that proficiency development is in part minimally linked to the individual learner's successful self-regulation which can be taught. One goal of language counseling in self-access centers is to identify learners' challenges in order to direct them in effective self-regulation. Matching learning problems with appropriate strategies requires that counselors have a clear framework for strategies and strategy instruction. 
One such framework is Oxford's (2011) Strategic Self-Regulation model (S $\left.{ }^{2} R\right)$. In brief, the $\mathrm{S}^{2} \mathrm{R}$ model is divided into two parts: metastrategies and strategies. Metastrategies refer to the learner's executive functions, his or her ability to adjust behaviors depending on the task or context and choose appropriate strategies; strategies refer to the learner's direct behaviors. The model further defines metastrategies and strategies in a tripartite classification system: metacognitive and cognitive strategies, meta-affective and affective strategies, and metasociocultural-interactive (SI) and SI strategies.

Learners have six distinct types of metaknowledge available to them which are similar to, and expand on, Winne and Perry's (2000) metacognitive knowledge dimension. The difference between the two is that in the $\mathrm{S}^{2} \mathrm{R}$ model, metaknowledge is not limited to metacognition, but can be applied to the categories of meta-affect and meta-SI (Oxford, 2011). These are: person knowledge (e.g., individual goals), group/culture knowledge (e.g., cultural expectations), task knowledge, whole-process knowledge (e.g., long-term learning goals), strategy knowledge, and conditional knowledge (i.e., knowledge of when to use a strategy and why).

The $\mathrm{S}^{2} \mathrm{R}$ model gives strategy researchers the ability to label and discuss learning strategies as they fall into the possible categories of metastrategies and strategies. For example, learners' use of flashcards or mobile devices for vocabulary review falls under cognitive strategies, while time management and study planning would be considered metacognitive strategies. A meta-affective strategy includes positive learner self-talk about learning progress; an affective strategy is the use of positive imagery of learner or task outcomes. A learner who seeks out opportunities to speak the second language (L2) is using a meta-SI strategy. By using gestures to overcome gaps in understanding, the learner employs an SI strategy. Together, metastrategies and strategies offer two broad classification systems to describe learner behaviors, a necessary first step to be able to systematically analyze areas of learner difficulty and then identify strategies and an approach to strategy instruction which can help learners self-regulate.

\section{Counseling for Language Learning}

Strategy instruction can be integrated into language programs in a variety of ways. Instruction can encompass a general skills course geared towards generic metacognitive strategies (e.g., awareness raising and study habits), or focus on specific language learning strategies (Cohen, 2003). Strategy workshops can be delivered outside of the normal language 
class, offering targeted, attention-raising training for particular language learning strategies (e.g., non-participatory listening) (Cohen, 2003; Oxford, 1990). Another approach is strategy-based instruction (SBI), an integrated method to strategy instruction; the teacher describes and models a strategy; the learner practices the strategy; and the class reflects on use (Cohen, 2003; Rubin, 2005; Rubin, Chamot, Harris \& Anderson, 2007).

The final method, language counseling, uses a more tailored approach than those outlined above by basing strategy instruction on the individual learner's needs. A language counselor works with a language learner to raise awareness of strengths and needs along with appropriate strategies which will better work to meet the learner's goals (Karlsson, Kjisik, \& Norlund, 2007; Mozzon-McPherson, 2007; Reinders, 2007). Self-access centers use counselors as facilitators in the learning process, coaching language learners facing challenges (Mozzon-McPherson, 2000). The counselor and student can collaboratively outline a plan with metastrategies and strategies to help the student develop strategic self-regulation and become more self-aware of learning processes (Mozzon-McPherson, 2007; Reinders, 2007).

One of the complexities of effective language counseling is that it requires counselors to familiarize themselves with challenges learners commonly experience, with the language learning process, and with both metastrategies and strategies. Faced with a variety of learners at different levels, the range of ongoing language and learning problems can make relevant advising difficult (Reinders, 2007). For example, a beginning Mandarin learner working with pinyin and characters has different learning needs than an advanced Spanish student working with pragmatics.

The purpose of the present study was to systematically analyze the historical data contained in counseling reports written for beginning Arabic language learners $(N=19)$ enrolled in an intensive, academic language program to discover what challenges this student population experienced. Trends were analyzed using the $\mathrm{S}^{2} \mathrm{R}$ model as a framework for understanding. The study focused on the research question: what types of challenges are documented by counselors and beginning Arabic learners in counseling reports? The answer should provide meaningful insight to language counselors concerned with targeted strategy instruction. 


\section{Methodology}

\section{Context and materials}

The current research project focused on a language counseling program in a self-access center developed to support adult foreign language learners in an intensive, academic foreign language program in a West Coast school in the United States. Students were enrolled in a foreign language program consisting of six hours of academic language instruction daily followed by two hours of evening homework. Students either voluntarily enrolled to receive language counseling services or were sent by their language teachers for help. The counseling program was developed to support students at various developmental stages of language learning by offering tailored strategy instruction in individual sessions with a language counselor. Each session was conducted face-to-face over one hour.

Counselors received a general training guide and strategy elicitation resources, such as the Strategy Inventory for Language Learning (SILL) (Oxford, 1990), but were not normed in the guidance provided to learners. Language counselors did not necessarily speak the target language the student was studying. Following are the guidelines counselors used for completing counseling reports:

In one or two paragraphs describe how you understand the academic struggles of the student. Your view of the root cause(s) of the student's difficulties may or may not be the same as the student's view. Briefly describe your student's vocational and/or academic background prior to starting the course and his/her learning goals.

And:

List strategies that address the student's language learning struggles. Include a brief rationale for your recommendations.

At the end of the session, counselors summarized the students' learning issues as well as suggested learning strategies in report format. Counselors concentrated on strategy use and independent learning resources, developing students' self-regulation abilities through an interactive dialogue. At the session's conclusion, the counselor produced a detailed language counseling report divided into three sections. The first section included a qualitative self- 
assessment from the learner consisting of perceived strengths, weaknesses, current strategies, and study habits. The second section consisted of the counselor's qualitative assessment of the learner's progress and challenges. The final section outlined tailored strategies, learning resources, and recommendations which the counselor and student had discussed during the session. For example, after reviewing class materials, and discussing current study habits, one counseling report included the following strategies for a student struggling with vocabulary memorization:

Write translations in the margins of the textbook, not above the word. This forces you to try and remember the vocabulary word instead of automatically having it there in front of you when you review for homework.

And:

Do spaced review of the vocabulary and presentations in the units over a period of two to three weeks. We discussed how the mind moves short term memory vocabulary into long term memory. Review during breaks, at lunch and in the evening before bed. Say the vocabulary out loud and focus on the illustrations, page layouts, titles, and notes written in the margin. Remember the funny stories, jokes, or comments your fellow classmates made during the hour. This way your memory uses not only the words, but the visual cues on the page and the auditory cues from class to help recall classroom discussions that were meaningful.

The counselor sent one copy of the tailored report to the student and archived another copy. This study used a nonexperimental, historical research design analyzing qualitative data contained in archived language counseling reports. Counseling reports included in the study $(N$ $=19$ ) were limited to archival data from 2010 and 2011. Eight different language counselors authored the reports. Report selection was non-random. All reports which contained completed student and counselor observations for beginning Arabic students seen between weeks 1 and 10 of the language program were included in the study. Any information which could be used to identify the learner was deleted and each report received a numerical code. 
SiSAL Journal Vol. 3, No. 4, December 2012, 438-451

\section{Coding methodology}

Using a systematic, two-cycle coding approach, descriptive coding was used during the first cycle of open coding to extract a categorized inventory of the data using lean codes (labels rephrased in the researcher's own words). Codes were developed using a constant-comparison approach, allowing the coded data from one report to be compared to that of another for either similarity or difference (Glaser \& Strauss, 1967; Strauss \& Corbin, 1988). The descriptive codes were developed using investigator triangulation, with two readers coding the reports separately and then triangulating the results for validity. Disagreement was resolved through reanalysis until 100\% agreement was achieved.

The second cycle of coding consisted of axial coding to analyze the data for invariant structures in the descriptive codes and collapsed into four major themes which were analyzed using frequency counts (Creswell, 2009; Saldaña, 2009). All of the open codes were charted which allowed codes to be rearranged into related categories.

\section{Results}

\section{Open coding}

The initial coding process resulted in 13 separate open codes. Table 1 illustrates codes developed during the first cycle of open coding, and shows a high incidence of issues related to vocabulary memorization. Indeed, the primary reason for every learners' language counseling session was trouble related to vocabulary, with one counseling report including the statement, "the pace is hard to maintain, with vocabulary retention the biggest challenge." This led to the lean code pace of vocabulary. The lean code vocabulary was used for students struggling with vocabulary memorization.

Table 1. Open coding codes and frequencies

\begin{tabular}{lc}
\hline Open Codes & $\boldsymbol{N}$ \\
\hline Pace of vocabulary & 6 \\
Decrease time studying & 7 \\
Learning Styles Mismatch & 4 \\
Can't distinguish words & 7 \\
Balance work/school & 1 \\
Improve study efficacy & 3 \\
Organized study time & 1 \\
Organization & 2
\end{tabular}


SiSAL Journal Vol. 3, No. 4, December 2012, 438-451

\begin{tabular}{lc} 
Study planning & 1 \\
Stress & 6 \\
Relaxation & 3 \\
Vocabulary & 18 \\
Trouble listening & 3 \\
\hline
\end{tabular}

Issues related to study and time management also occurred with high levels of frequency. For example, during the first cycle of coding, the lean code for improve study efficacy came from the report data "[student] was looking for how to improve his time spent studying". The lean code decrease time studying was used in reference to learners' reporting long hours spent on homework. Organized study time referred to a report focused on helping a learner to prioritize learning tasks. Study planning referred to a student who needed to develop a detailed learning plan. The lean code organization was used for references to learners' who needed help with general organization skills (e.g., using a day planner). The code balancing work/school came from a report where the learner expressed anxiety over competing job and school demands. The code learning styles mismatch referred to materials design or teaching styles which were mismatched with the student's preferred learning style.

The third problem area for students was listening. As a discrete skill, listening was divided into two separate categories: the inability to hear words (coded as can't distinguish words), and general, non-descript problems with listening (coded as trouble listening).

The final problem area for students was stress. The initial descriptive lean codes for stress were stress and relaxation. For example, the lean code stress was used for '[the course] has produced a tremendous amount of stress in [the student's] daily life.' Another report included, '[the student] is experiencing real difficulties in dealing with stress.' Conversely, '...eat well and get enough sleep. If [the student] is not taking care of himself physically and emotionally, he will not finish' was coded as relaxation.

\section{Axial coding}

Four major themes emerged from the axial coding: vocabulary, aural discrimination, stress, and study management. Vocabulary encompassed any references to challenges relating to learning vocabulary (e.g., 'The learner is seeking effective was to study Arabic vocabulary.'). Aural discrimination referenced any challenges relating to listening in the language (e.g., 'The 
learner has trouble hearing words and individual sounds.'). Descriptive data directing the student to relax (e.g., 'Relax! If you are stressed out and tired, it makes remembering information much more difficult.'), as well as the lean codes for stress were combined into the stress theme during axial coding. Here, one of the initial lean codes generated in the first cycle became a main category in the final axial coding. The final category, study management, included any reference to study habits, balancing learning styles, or time management (e.g., 'The learner is spending long hours on fruitless self-study.'). Table 2 shows the final axial codes, corresponding open codes, and frequencies.

Table 2. Axial Codes and Corresponding Open Codes

\begin{tabular}{|c|c|c|c|c|c|c|c|c|}
\hline & Vocabulary & $N$ & Study Management & $N$ & $\begin{array}{l}\text { Aural } \\
\text { Discrimination } \\
\end{array}$ & $N$ & Stress & $N$ \\
\hline & Vocabulary & 18 & $\begin{array}{l}\text { Decrease time } \\
\text { studying }\end{array}$ & 7 & $\begin{array}{l}\text { Can't distinguish } \\
\text { words }\end{array}$ & 7 & Stress & 6 \\
\hline & \multirow[t]{6}{*}{$\begin{array}{l}\text { Pace of } \\
\text { vocabulary }\end{array}$} & 6 & $\begin{array}{l}\text { Learning style } \\
\text { mismatch }\end{array}$ & 4 & Trouble listening & 3 & Relaxation & 3 \\
\hline & & & Balance work/school & 1 & & & & \\
\hline & & & $\begin{array}{l}\text { Improve study } \\
\text { efficacy }\end{array}$ & 3 & & & & \\
\hline & & & Organized study time & 1 & & & & \\
\hline & & & Organization & 1 & & & & \\
\hline & & & Study planning & 1 & & & & \\
\hline Total & & 24 & & 18 & & 10 & & 9 \\
\hline
\end{tabular}

\section{Discussion}

This study was designed as exploratory research using a qualitative lens examining the challenges beginning Arabic learners commonly experience. The data analysis produced four main themes for this population: vocabulary, study management, aural discrimination, and stress. These themes highlight the multidimensional reality of language learning and the need for distinctive forms of self-regulation.

The findings can be better understood using Oxford's $\mathrm{S}^{2} \mathrm{R}$ model (2011), specifically with the cognitive and affective dimensions to improve learners' self-regulation. Learners faced challenges with language learning, general learning, and affect mediation. Language learning challenges included vocabulary and aural discrimination problems. Study management falls under the general executive and cognitive functions which students employ for effective 
learning. Study management skills apply to any student, regardless of discipline. Under affect, stress emerged as a major theme, underscoring the need for further investigation on its role in this context. At a minimum, counselors interacting with similar student populations should be aware of these trends and their implications for targeted strategy instruction discussed below.

\section{Implications for language learning self-regulation}

Vocabulary memorization and aural discrimination both emerged as challenging areas for learners. There is evidence of a connection between the two themes in the literature. BundgaardNielsen, Best and Tyler (2011) examined the trajectory of phonetic and phonological perception in adult L2 learners in an intensive environment and found that significant changes in the student's ability to accurately discriminate between phonemes can occur in an intensive program within the first 12 weeks. The current study's findings seem to support their research. The researchers also found that the larger a second language learner's vocabulary, the more consistently the learner could accurately discriminate vowel contrasts in the L2. Interestingly, length of target language exposure did not result in an automatic, increased ability to discriminate between phonemes. The inference here is that directing the learner to strategies which broaden vocabulary rather than to additional listening resources should improve the individual's listening skills.

When it comes to learning vocabulary, however, the ability to retain quality phonological sequences of L2 input for short periods of time is a necessary pre-requisite to transferring vocabulary into long-term memory (Kempe \& Brooks, 2011). Students who are better at the short-term phonological retention (e.g., ability to remember how the language sounds) are better at learning vocabulary (Kempe \& Brooks, 2011). Phoneme discrimination is an essential requisite to successful vocabulary acquisition which in turn augments listening skills.

From a language educator's standpoint, the traditional emphasis in listening is on higherlevel comprehension tasks which tend to focus on the product of listening, rather than the process (Field, 2003). Learners may be able to arrive at a correct answer, yet still be unable to fully comprehend a passage, complaining to counselors about the inability to hear words. This is learner-identified breakdown. The ability to determine where word boundaries fall is a greater problem with language learners than practitioners generally recognize (Field, 2003). Lexical segmentation depends entirely on the learner's capacity to correctly discriminate between phonemes. 
Segmentation is a low-level skill which develops during the initial stages of the language acquisition process, which may be why it appears as a major theme in the current study. Field (2003) described the early stages of the listening process as learners develop the strategy of scanning aural input for familiar sounds and matching them to known words in their lexicons, creating elaborate stories so that the sounds they hear will make sense. Once a student has come up with an incorrectly segmented word, the student ignores what follows to logically support the previous lexical item (Field, 2003). Awareness-raising activities, for example dictation exercises, alert learners' to the dangers of faulty segmentation.

While simple dictation alone is not an effective strategy to improve listening comprehension (Jafarpur \& Yamani, 1993), targeted dictation can help students develop phonemic awareness. Field (2003) suggested students practice phrase dictation using ambiguous word boundaries to raise learners' awareness of segmentation. Counselors must keep in mind that language learners have set expectations and preconceived ideas of how language should sound influenced by the written language (Field, 2003). Guiding learners to authentic, self-study listening resources where they must use syntax to distinguish the weak forms, reductions, and contractions can be useful in helping to develop segmentation skills. Learners can be told explicitly the rationale behind dictation is to practice segmentation, and encouraged to play difficult audio passages repeatedly to puzzle out word boundaries. The goal of dictation is not to arrive at the correct answer for a content question, but rather to develop phonemic awareness.

\section{Implications for metacognitive self-regulation}

Self-regulation in language learning refers to the processes a learner uses to exercise control over learning, and the term is often used synonymously with autonomy, self-directed behavior, self-control, and self-management (Cohen, 2007; Dörnyei, 2005). Many issues related to metacognitive self-regulation, coded as self-management, emerged from the data analysis. The ability to self-manage is a metacognitive strategy all students employ. During the counseling sessions, learners received guidance on study planning, time management, balancing learning styles, organization, and balancing work/school demands, all of which fall under metacognitive strategies. Intensive foreign language programs require students to cope with strenuous workloads and established, fast-paced curricula. Resources and support services for general study skills are typical of academic orientation programs offered to first year undergraduate 
learners. The findings suggest value in future research investigating the need for this area of skill development for these language learners. At a minimum, counselors should be aware that learners may be struggling to cope with course demands and require general metacognitive strategy support not specifically related to language learning.

\section{Implications for affective self-regulation}

Stress management reoccurred frequently as a major theme, either explicitly or implicitly, in the counseling reports, highlighting the role of affect and the need for meta-affective and affective strategies. For language learners, affective variables are at least as important as aptitude when predicting language learning achievement (Gardner, 1985; Scovel, 2000). There are many possible factors which could be contributors to student stress. For example, students may have felt pressured and distressed with their inability to meet program demands early on in an intensive course. While this study did not look at the correlation between the need for affective and metacognitive self-regulation strategies, the findings suggest the value of examining this correlation in future research. Counselors should be mindful of stress as an area for targeted affective strategy instruction with a potential cross-over in the need for metacognitive strategy coaching.

\section{Conclusions}

The current research project served as an initial look at problems facing beginning language learners in an intensive foreign language program. The study was intentionally limited in scope because of its exploratory nature. As such, findings are limited to the current population, which consisted of beginning Arabic learners in an intensive language program experiencing learning difficulties. While trends suggested that learners experienced similar obstacles, future research should be expanded to include different languages and proficiency levels.

Future researchers should explore if and how the four major themes of vocabulary, aural discrimination, stress, and self-management are interconnected. To advance practical applications of theory, future research should include how researchers can employ the $S^{2} R$ model effectively to develop a more encompassing approach to guiding students towards strategic learning by addressing metastrategies and strategies in relation to learners' needs. 
SiSAL Journal Vol. 3, No. 4, December 2012, 438-451

This study used the basic elements of the $S^{2} R$ model as a framework to understand learner difficulties. While the goal of language counseling remains to offer individual students tailored strategy instruction, initial findings suggest that trends exist. Awareness of trends could inform the pre- and in-service training which language counselors receive. At a minimum, counselors should be cognizant of the common problem areas learners experience in a particular program and be prepared with appropriate metastrategies, strategies, and resources.

\section{Notes on the contributor}

Erin O'Reilly is an Associate Professor at the Defense Language Institute Foreign Language Center. Her research interests include language learning counseling, affective variables and strategy use, and learner autonomy. Contents of this paper are not necessarily the official views of, or endorsed by, the U.S. Government, DoD, Department of the Army, or DLIFLC.

\section{References}

Bundgaard-Nielsen, R., Best, K., \& Tyler, M. (2011). Vocabulary size is associated with secondlanguage vowel perception performance in adult learners. Studies in Second Language Acquisition, 33, 433-461. doi:10.1017/S0272263111000040

Cohen, A. D. (2003, August). Strategy training for second language learners. Minneapolis: Center for Advanced Research on Language Acquisition, University of Minnesota. (ERIC Document Reproduction Services No. EDO-FL-03-02)

Cohen, A. D. (2007). Language learner strategies. A. Cohen and E. Macaro (Eds.). Oxford, UK: Oxford University Press.

Creswell, J. (2009). Research design: Quantitative, qualitative, and mixed methods approach. Thousand Oaks, CA: Sage Publications.

Dörnyei ,Z. (2005). The psychology of the language learner: Individual differences in second language acquisition. Mahwah, NJ: Erlbaum.

Field, J. (2003). Promoting perception: Lexical segmentation in L2 listening. ELT Journal, 54(7), 325-334. doi:10.1093/elt/57.4.325

Gardner, R. (1985). Social psychology and second language learning: The role of attitudes and motivation. London, UK: Arnold.

Glaser, B. G., \& Strauss, A. L. (1967). The discovery of grounded theory. Chicago, IL: Aldine. 
Jafarpur, A., \& Yamani, M. (1993). Does practice with dictation improve language skills? System, 21(3), 359-369. doi:10.1016/0346-251X(93)90026-D

Karlsson, L., Kjisik, F., \& Norlund, J. (2007). Language counseling: A critical and integral component in promoting an autonomous community of learning. System, 35(1), 46-65. doi:10.1016/j.system.2006.10.006

Kempe, V., \& Brooks, P. (2011). Individual differences in adult second language learning: A cognitive perspective. Scottish Language Review, 25, 15-22.

Mozzon-McPherson, M. (2000). Promoting and supporting independent learning out of the classroom: An analysis of the skills of advising and their implications on the emerging role of language learning advisors. Links \& Letters, 7, 111-126.

Mozzon-McPherson, M. (2007). Introduction to special issue: Language counseling. System, 37, 66-92.

Oxford, R. (1990). Language learning strategies: What every teacher should know. New York, NY: Newbury House.

Oxford, R. (2011). Teaching and researching language learning strategies. Harlow, UK: Pearson.

Reinders, H. (2007). Big brother is helping you: Supporting self-access language learning with a student monitoring system. System, 35(1), 93-111. doi:10.1016/j.system.2006.10.009

Rubin, J. (2005). The expert language learner: A review of good language learner studies and learner strategies. In K. Johnson (Ed.), Expertise in second language learning and teaching (pp. 37-63). Basingstoke, UK: Palgrave Macmillan.

Rubin, J., Chamot, A. U., Harris, V., \& Anderson, N. (2007). Intervening in the use of strategies. In A. D. Cohen \& E. Macaro (Eds.), Language learner strategies: 30 years of research and practice (pp. 29-45). Oxford, UK: Oxford University Press.

Saldaña, J. (2009). The coding manual for qualitative researchers. Thousand Oaks, CA: Sage Publications.

Scovel, T. (2000). Learning new languages: A guide to second language acquisition. Boston, MA: Heinle \& Heinle.

Strauss, A., \& Corbin, J. (1988). Grounded theory methodology: An overview. In N. K. Denzin \& Y. Lincoln (Eds.), Strategies of qualitative inquiry (pp. 158-183). Newbury Park, CA: Sage.

Wilson, M. (2003). Discovery listening - improving perceptual processing. ELT Journal, 54(7), 335-343. doi:10.1093/elt/57.4.335 
SiSAL Journal Vol. 3, No. 4, December 2012, 438-451

Winne, P., \& Perry, N. (2000). Measuring self-regulated learning. In M. Boekaerts, P. Pintrich \& M. Zeidner (Eds.), Handbook of self-regulation (pp. 531-566). San Diego, CA: Academic Press. 